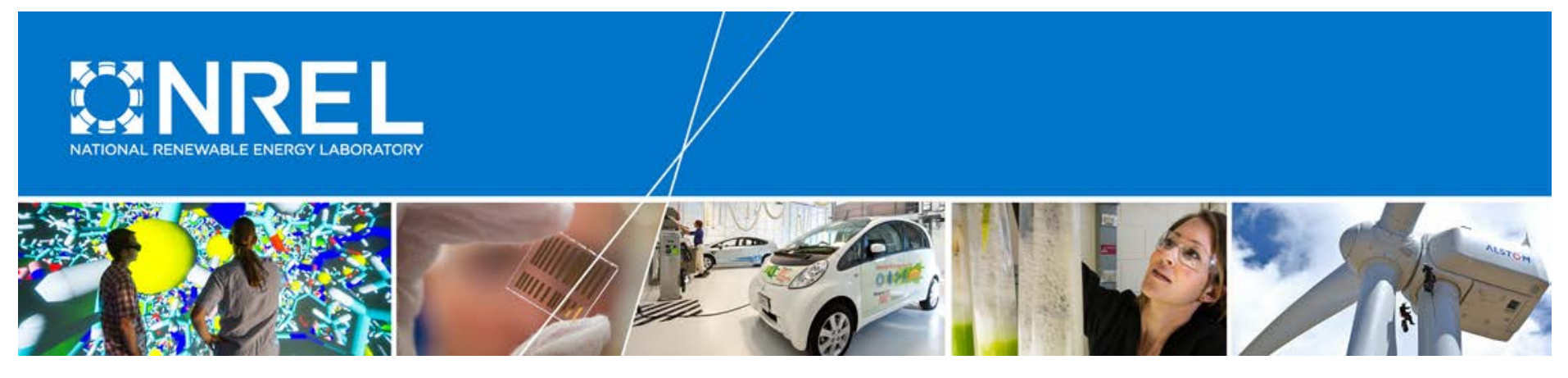

\title{
Industry Perspectives on Advanced Inverters for U.S. Solar Photovoltaic Systems: Grid Benefits, Deployment Challenges, and Emerging Solutions
}

Emerson Reiter, Kristen Ardani, and Robert Margolis

National Renewable Energy Laboratory

Ryan Edge

Solar Electric Power Association

NREL is a national laboratory of the U.S. Department of Energy Office of Energy Efficiency \& Renewable Energy Operated by the Alliance for Sustainable Energy, LLC

This report is available at no cost from the National Renewable Energy Laboratory (NREL) at www.nrel.gov/publications.

Technical Report

NREL/TP-7A40-65063

September 2015 


\section{Industry Perspectives on Advanced Inverters for U.S. Solar Photovoltaic Systems: Grid Benefits, Deployment Challenges, and Emerging Solutions}

Emerson Reiter, Kristen Ardani, and

Robert Margolis

National Renewable Energy Laboratory

Ryan Edge

Solar Electric Power Association

Prepared under Task No. SM13.0532

NREL is a national laboratory of the U.S. Department of Energy Office of Energy Efficiency \& Renewable Energy Operated by the Alliance for Sustainable Energy, LLC

This report is available at no cost from the National Renewable Energy Laboratory (NREL) at www.nrel.gov/publications.

National Renewable Energy Laboratory 15013 Denver West Parkway Golden, CO 80401

303-275-3000 • www.nrel.gov
Technical Report

NREL/ TP-7A40-65063

September 2015

Contract No. DE-AC36-08G028308 


\title{
NOTICE
}

This report was prepared as an account of work sponsored by an agency of the United States government. Neither the United States government nor any agency thereof, nor any of their employees, makes any warranty, express or implied, or assumes any legal liability or responsibility for the accuracy, completeness, or usefulness of any information, apparatus, product, or process disclosed, or represents that its use would not infringe privately owned rights. Reference herein to any specific commercial product, process, or service by trade name, trademark, manufacturer, or otherwise does not necessarily constitute or imply its endorsement, recommendation, or favoring by the United States government or any agency thereof. The views and opinions of authors expressed herein do not necessarily state or reflect those of the United States government or any agency thereof.

This report is available at no cost from the National Renewable Energy Laboratory (NREL) at www.nrel.gov/publications.

Available electronically at SciTech Connect http:/www.osti.gov/scitech

Available for a processing fee to U.S. Department of Energy and its contractors, in paper, from:

\author{
U.S. Department of Energy \\ Office of Scientific and Technical Information \\ P.O. Box 62 \\ Oak Ridge, TN 37831-0062 \\ OSTI http://www.osti.gov \\ Phone: 865.576.8401 \\ Fax: 865.576.5728 \\ Email: reports@osti.gov
}

Available for sale to the public, in paper, from:

\author{
U.S. Department of Commerce \\ National Technical Information Service \\ 5301 Shawnee Road \\ Alexandria, VA 22312 \\ NTIS http://www.ntis.gov \\ Phone: 800.553 .6847 or 703.605 .6000 \\ Fax: 703.605.6900 \\ Email: orders@ntis.gov
}




\section{Acknowledgments}

The authors thank the following individuals and organizations for their contributions to and review of this work: John Berdner (Enphase), Kenneth Boyce (Underwriters Laboratory), Michael Coddington (National Renewable Energy Laboratory), Babak Enayati (National Grid), Tracy Miehlke (PJM), Houtan Moaveni (New York Power Authority), Erika Myers (Solar Electric Power Association), John Sterling (Solar Electric Power Association), Jarrett Zuboy (consultant). In particular, we thank Miriam Makhyoun (formerly with Solar Electric Power Association) for her help in developing the interview protocol and setting up the interviews. This work was supported by the U.S. Department of Energy under contract number DE-AC36$08 \mathrm{GO} 28308$. 


\section{List of Acronyms}

AGC

AMI

AMR

APS

AZCC

CAGR

CEC

CPUC

DER

DGPV

DRP

IEEE

NEC

NREL

PCC

PV

SEPA

SIWG

TEP

UL

VAR

WEIL automatic generator control

advanced metering infrastructure

automatic meter reading

Arizona Public Service

Arizona Corporation Commission

compound annual growth rate

California Energy Commission

California Public Utilities Commission

distributed energy resource

distributed-generation PV

distribution resource plan

Institute of Electric and Electronics Engineers

National Electrical Code

National Renewable Energy Laboratory

point of common coupling

photovoltaic

Solar Electric Power Association

Smart Inverter Working Group

Tucson Electric Power Company

Underwriters Laboratories

volt-ampere reactive

Western Electric Industry Leaders 


\section{Executive Summary}

As the penetration of distributed-generation photovoltaics (DGPV) has risen rapidly in recent years, utilities and other electric-system stakeholders have become increasingly concerned about the resulting impacts on grid reliability. At the same time, advanced inverters - which can modulate output and communicate actively with grid operators - are increasingly seen as a way to enhance grid stability and enable wider adoption of DGPV. Nearly half of the utilities that responded to a 2015 Solar Electric Power Association (SEPA) survey question about advanced inverters were either implementing or considering an advanced inverter project. Despite the interest in advanced inverters, however, relatively few utilities have widely deployed the devices to date.

To clarify current utility strategies and other considerations related to advanced inverter deployment, we interviewed 20 representatives from 11 leading organizations closely involved with advanced inverter pilot testing, protocols, and implementation. Included were representatives from 7 utilities, a regional transmission operator, an inverter manufacturer, a leading solar developer, and a consortium for grid codes and standards. Interview data represent geographically the advanced inverter activities identified in SEPA's prior survey results - most interviewed utilities serve California, Arizona, and Hawaii, though we also interviewed others from the Northeast, Mid-Atlantic, and Southeast.

Interview participants identified several benefits they expect from advanced inverters as well as several challenges to implementing the technology.

- Benefits
○ Improvement in system reliability and power quality
- Increase in distribution system visibility through sensor data
○ Potential deferral of utility grid capital investments.

\section{- Challenges}

○ Involvement in ongoing, multi-party engagement

- Inability of standards to keep pace with technological advances

- Need for new communications infrastructure and protocols

○ Lack of compensation mechanisms for ancillary services.

This report provides additional context on the latter three challenges - which the participants identified as being the most important_ — and discusses emerging solutions.

The updating of electric-system standards generally proceeds slowly and deliberately, and the outdated versions of two particular standards - UL 1741 (addressing equipment safety) and IEEE 1547 (addressing interconnection) — are delaying use of advanced inverters nationwide.

However, California's urgent need to accelerate advanced inverter deployment is helping stimulate sweeping revisions of the standards. We anticipate these pending updates will not only protect individual systems and the grid from the new functions of advanced inverters, but will also enable the inverters to provide active grid support. Additionally, the updated standards will likely promote progress toward the mass-production of advanced inverters in which a common 
set of advanced functions has already been enabled, satisfying the desire indicated by interview participants for "off-the-shelf" products. In any case, the updates should eliminate the standardsrelated barriers to advanced inverter deployment.

Another critical challenge is establishing the communications capabilities needed to realize the grid-support potential of advanced inverters. Many communications options are available, and as the capabilities of the options increase so does the cost. To balance the cost-benefit tradeoff, some of the utilities we interviewed are planning hybrid approaches that relegate advanced inverters in certain areas to autonomous or low-bandwidth operation while enabling robust connectivity on inverters in other areas. Overall, utility participants agreed that the benefits of establishing communications infrastructure for advanced inverters outweigh the associated complexity and costs.

Lastly, the lack of mechanisms to compensate non-utility photovoltaic (PV) owners for providing ancillary services presents a challenge to realizing the full potential of advanced inverters. Some utilities are experimenting with utility ownership and control of PV systems mounted on customers' rooftops. Under this framework, utilities may be able to streamline operational logistics, avoid complex financial compensation issues, and more quickly assess the value of the services received from the advanced inverter-enabled systems. Results from such projects then can inform the development of future mechanisms for compensating non-utility PV owners. This is important because non-utility ownership seems likely to remain the dominant form of distributed PV deployment in the foreseeable future. 


\section{Table of Contents}

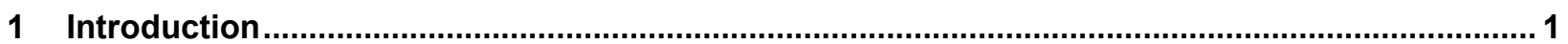

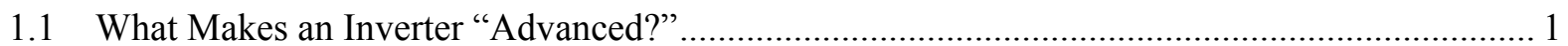

1.2 Advanced Inverter Deployment Trends ......................................................................... 2

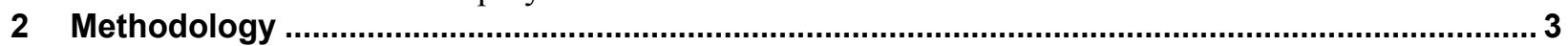

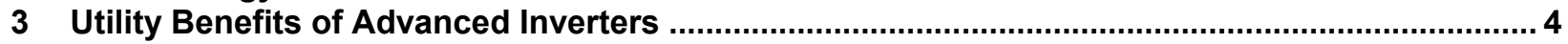

3.1 Improvement in System Reliability and Power Quality ......................................................... 4

3.2 Increase in Distribution System Visibility Through Sensor Data .............................................. 5

3.3 Potential Deferral of Utility Grid Capital Investments........................................................... 5

4 Advanced Inverter Deployment Challenges and Emerging Solutions......................................... 5

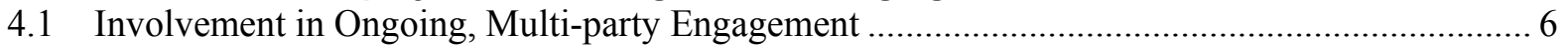

4.2 Inability of Standards to Keep Pace with Technological Advances.......................................... 6

4.2.1 California Rule 21 and the Smart Inverter Working Group ........................................... 7

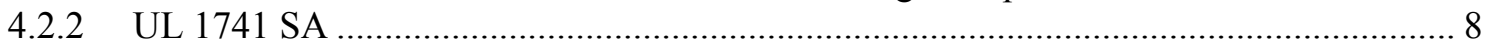

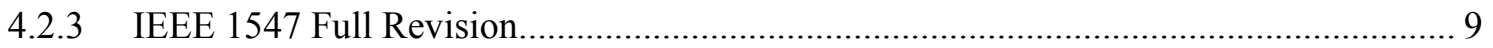

4.3 Need for New Communications Infrastructure and Protocols .................................................. 9

4.3.1 Relationship Between Advanced Functionality and Communications ......................... 10

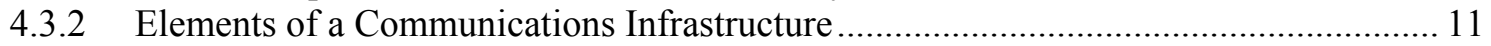

4.4 Lack of Compensation Mechanisms for Ancillary Services …............................................... 12

5 Arizona's Deployment Strategies and Solution Pathways......................................................... 13

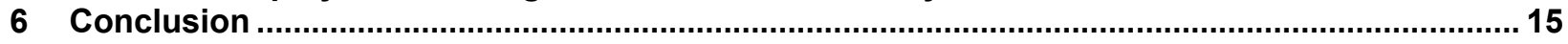

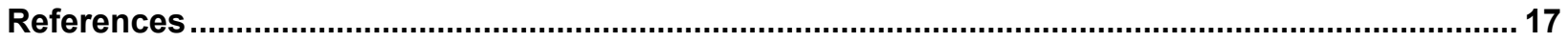

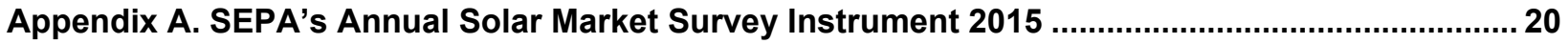

Appendix B. Utilities Implementing or Exploring Advanced Inverters (from SEPA 2015 Survey) ... 21

Appendix C. NREL-SEPA Interview Questions Used for Data Collection ......................................... 23

Appendix D. Overview of Advanced Inverter Deployment Standards............................................... 26

Appendix E. Description of Communication Layer Options ...................................................... 28 


\section{List of Figures}

Figure 1. Map of utilities implementing or considering implementing advanced inverters (Source: SEPA 2015 utility survey) ............................................................................................. 3

Figure 2. How regulations for distributed generation depend on IEEE 1547 and UL 1741_.................... 7

\section{List of Tables}

Table 1. Select Common Functions of Advanced Inverters .................................................................. 2

Table 2. Autonomous Versus Non-Autonomous Inverter Functions....................................................... 11

Table 3. Utility Options for Communications Infrastructure ............................................................. 12 


\section{Introduction}

Unprecedented reductions in solar photovoltaic (PV) equipment costs have driven rapid growth in the U.S. distributed-generation PV (DGPV) market, from $\sim 4.3 \mathrm{GW}$ of total installed capacity in 2012 to $\sim 10.0 \mathrm{GW}$ as of the second quarter of 2015 . This represents a $45 \%$ compound annual growth rate (CAGR) in the residential market and a 44\% CAGR in the commercial market (BNEF 2014, Deutsche Bank Markets Research 2015, GTM Research and SEIA 2015).

Large quantities of DGPV can challenge utility-grid reliability by increasing the variability and uncertainty of the system net load and increasing the potential for overvoltages (Denholm et al. 2014). Advanced or "smart" inverters could address many of these challenges by actively mitigating unwanted grid impacts caused by DGPV, thus enabling wider adoption of PV and ensuring grid stability. In August 2013, top executives from 16 of the largest utilities in the western United States - collectively the Western Electric Industry Leaders (WEIL) - signed on to support advanced inverter functionality for all new solar interconnections (WEIL Group 2013). Also in 2013, the California Public Utilities Commission (CPUC) began the process of amending Rule 21 in parallel with the Institute of Electric and Electronics Engineers' (IEEE) update to its IEEE 1547 standard. Both Rule 21 and IEEE 1547 govern the interaction of inverters with the grid, and the revisions to both will enable advanced inverter functionality. Since 2013, Rule 21 and IEEE 1547 have undergone limited updates or amendments, but more significant changes are still pending, and some utilities are moving forward with their own pilot programs to test the grid-support functions of advanced inverters. Despite these ongoing efforts, however, technical barriers continue to prevent broad adoption of advanced inverters, and policy and business models still must evolve to maximize the technology's potential.

This report clarifies emergent protocols and considerations for advanced inverter deployment. The remainder of this introduction defines advanced inverter functionality and characterizes broad deployment trends as context for our interview results. Section 2 describes our methodology. Section 3 summarizes the advanced inverter benefits discussed in our interviews. Section 4 summarizes the challenges to advanced inverter deployment from our interviews, provides context on key challenges, and discusses actual and potential solutions. Section 5 illustrates advanced inverter deployment challenges and solutions through the experience of two Arizona utilities. Finally, Section 6 concludes and identifies areas for future research.

\subsection{What Makes an Inverter "Advanced?"}

All inverters used in grid-connected PV systems convert electricity from a direct-current source to alternating-current output that matches the voltage, frequency, and phase of the interconnected utility grid to ensure safety and reliability. Under current electrical codes and standards, inverters must cease to energize the grid if frequency and voltage fall outside of set parameters, and they cannot actively change the voltage of the grid without coordination with the local electric utility.

Advanced inverters, in contrast, can modulate their output to actively support the grid in many novel ways. They can continue to operate within wider ranges of frequency and voltage, they can vary their power factor, and they can enhance the power quality and performance of the local grid. For instance, previous studies have shown that up to $100 \%$ more PV can be accommodated using advanced reactive power controls such as volt-VAR and constant power factor (e.g., Coddington et al. 2012). An advanced inverter's physical hardware is virtually identical to that of 
standard inverters; the key differences are dictated by the software that governs the advanced functionality. Table 1 provides a select list of common advanced inverter functions (Seal 2014).

Table 1. Select Common Functions of Advanced Inverters

\begin{tabular}{ll}
\hline Function & Description \\
\hline Connect/disconnect & Physically connects or disconnects from the grid \\
\hline Adjust maximum generation level & Sets maximum generation \\
\hline Adjust power factor & Issues a power factor angle value \\
\hline Volt-VAR mode & Adjusts reactive power output \\
\hline Frequency ride-through & Sets the frequency parameters for operation \\
\hline Voltage ride-through & Sets the voltage parameters for operation \\
\hline Event/history logging & Requests event logs \\
\hline Status reporting & Requests inverter status \\
\hline
\end{tabular}

Direct costs for advanced inverter implementation are expected to be negligible for U.S. electric utilities. Most advanced functions can be enabled by manufacturers at virtually no cost because the inverters are controlled by embedded firmware that easily can be modified according to grid codes or hardware standards (such as Rule 21, IEEE 1547, and UL 1741, covered in section 4.2, below). Deploying telecommunications infrastructure or retrofitting existing inverters, however, adds substantial costs. Additionally, oversizing inverters to enable reactive power support without a reduction in real power output can increase the inverter cost for a given PV system.

\subsection{Advanced Inverter Deployment Trends}

In the first quarter of 2015, the Solar Electric Power Association (SEPA) surveyed 274 utilities about their solar activities (SEPA 2015). Of the 122 responses, 15 utilities said they were currently implementing a project or program involving advanced inverters, and another 43 said they were planning, considering, or researching deployment of advanced inverters in some capacity (see Appendix A for the SEPA survey language). Thus, nearly half of those responding to this question viewed advanced inverters as a component of their solar strategies in the coming years.

Most of the 15 utilities who responded to the SEPA survey indicated that they are currently implementing advanced inverters to serve the states with the most mature solar markets, such as Hawaii, California, and Arizona. Additionally, National Grid in the Northeast, subsidiaries of Pepco in the mid-Atlantic, and Avista Utilities in the Northwest are pursuing the technology. Duke Energy, Public Service Electric \& Gas, Los Angeles Department of Water and Power, and Austin Energy are among the 43 utilities planning, considering, or researching deployment of advanced inverters in some capacity.

Figure 1 summarizes SEPA's survey findings related to advanced inverter deployment. A complete list of respondents that were implementing or exploring advanced inverters is included in Appendix B. 


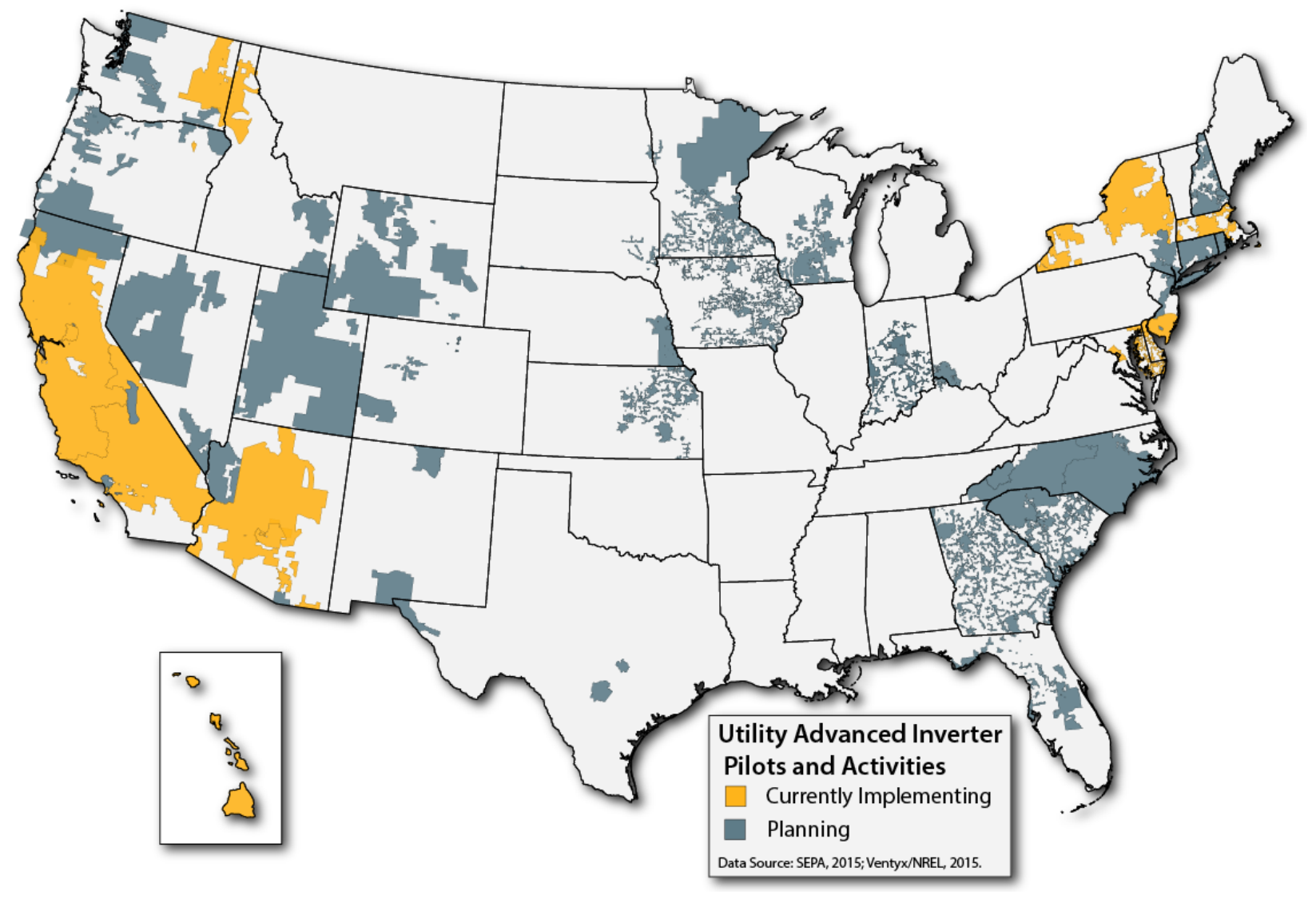

Figure 1. Map of utilities implementing or considering implementing advanced inverters (Source: SEPA 2015 utility survey).

\section{Methodology}

To date, most advanced inverter literature has addressed the functions of the technology (Seal 2014) and the associated grid benefits utilities seek (Davidovich and Sterling 2014). Much has also been written about Germany's recent system-wide advanced inverter retrofit (Wirth 2015, EPRI 2014). This literature effectively frames the challenges of integrating large concentrations of intermittent resources and some of the mitigation measures inverters can provide. Other literature generally describes the remaining regulatory and technological barriers to DGPV adoption, including the need for utility and solar industry business models to evolve so that advanced inverters can facilitate solar resource integration (Bird et al. 2013). Less has been written about real-world performance or implementation in the United States, because deployment has been limited. This report addresses gaps in the literature by summarizing the current state of active utility initiatives and pilot projects, discussing stakeholders' perceptions of the benefits of advanced inverters, describing the recent evolution of rules and standards governing advanced inverter use, identifying the short- and long-term market barriers to widescale adoption, and providing real-world examples of solutions to the barriers identified. 
To capture these insights, the National Renewable Energy Laboratory (NREL) and SEPA interviewed 20 representatives from 11 leading organizations closely involved with advanced inverter pilot testing, protocols, and implementation. Included were representatives from 7 utilities, a regional transmission operator, an inverter manufacturer, a leading solar developer, and a consortium for grid codes and standards. Interview data represent geographically the advanced inverter activities identified in SEPA's prior survey results - most interviewed utilities serve California, Arizona, and Hawaii, though we also interviewed others from the Northeast, Mid-Atlantic, and Southeast. Interview questions focused on gaining a deeper understanding of the benefits utilities seek from advanced inverter functions, current challenges to advanced inverter deployment, and the status of rules and standards governing inverter use. The full list of interview questions is included in Appendix C. Aggregate results in the following two sections highlight common themes and key takeaways from the interviews, but individual participant information remains confidential.

\section{Utility Benefits of Advanced Inverters}

The interview results reveal several common themes related to the utility benefits of advanced inverters, which are discussed in this section:

- Improvement in system reliability and power quality

- Increase in distribution system visibility through sensor data

- Potential deferral of utility grid capital investments.

\subsection{Improvement in System Reliability and Power Quality}

Nearly all utility representatives who participated in the interviews indicated a strong interest in using advanced inverter functionality to maintain system reliability and local power quality while increasing the contribution of DGPV to the generation portfolio. Specifically, utilities with high DGPV penetration commonly sought expanded voltage and frequency ride-through capabilities. These two functions were often characterized as "low-hanging fruit," meaning that the utilities could realize significant system benefits at a low implementation cost; the inverters can provide the ride-through support autonomously and without potentially expensive data connectivity with the utility. Currently, both the Phase 1 recommendations of the Smart Inverter Working Group (SIWG) for California's Rule 21 update and the 2014 amendment to IEEE 1547 (IEEE 1547a2014) establish frameworks for grid-tied PV systems to deliver expanded voltage and frequency ride-through.

More advanced power-quality features require more robust software and communications solutions that enable utilities to maximize advanced inverters' capabilities (see Section 4.3). The utilities interviewed expressed broad interest in tapping distributed inverters for volt-ampere reactive (VAR) support as a voltage-control tool, but their planned approaches differed. Some described a static, non-unity power factor for inverters on feeders with consistent voltage characteristics, whereas others would alter the power factor seasonally or even dynamically when integrated with a distribution management system or distributed energy resource (DER) management system. 


\subsection{Increase in Distribution System Visibility Through Sensor Data}

Many utility participants anticipate using telemetry data from inverters deployed across the distribution system to optimize grid operations, increase visibility, improve DER integration, and reduce overall operating costs for the distribution system. Many participants, however, cautioned that gathering such granular data can pose collection, storage, and processing challenges if the data are used to inform distribution-management practices (see Section 4.3). Gathering and storing such data also necessitates a conversation regarding data privacy and cybersecurity.

\subsection{Potential Deferral of Utility Grid Capital Investments}

Interconnecting DGPV to the utility's grid may necessitate adding or upgrading transformers, wires, voltage-regulation devices, control systems, and protection equipment (Denholm et al. 2014). Voltage-regulation devices, in particular, are subject to additional wear and tear with DGPV because of the increased potential for over-voltages as well as daily, weather-dependent voltage fluctuations. Nearly all of the utilities interviewed mentioned the potential for advanced inverter power electronics to defer capital investments in the distribution system, as advanced inverters can actively regulate voltage on a distribution feeder in lieu of other devices. This can mitigate PV-induced voltage impacts and obviate the need for some, or all, of the traditional voltage-control equipment (Varma, Das, and Vanderheide 2011). Additionally, a subset of utilities interviewed expressed an interest in validating whether DGPV with advanced inverters can reduce transmission-level capital investments. As Denholm et al. (2014) observe, for instance, at the transmission level,

DGPV with advanced inverters can reduce the quantity of reactive power required from generators. This in turn allows generators to run at a higher (real) power output level, reduces transmission losses, and can increase the (real) power capacity of transmission lines by reducing the current flow from reactive power oscillations.

\section{Advanced Inverter Deployment Challenges and Emerging Solutions}

Despite responses - from the 2015 SEPA survey and our interviews - indicating a strong utility interest in advanced inverters, few utilities have deployed or required the deployment of such inverters to date. Our results reveal several common themes related to the challenges of deploying advanced inverters, which help explain this discrepancy between interest and deployment:

- Involvement in ongoing, multi-party engagement

- Inability of standards to keep pace with technological advances

- Need for new communications infrastructure and protocols

- Lack of compensation mechanisms for ancillary services.

This section discusses interview responses related to these challenges, including emerging solutions. For the latter three challenges - which participants identified as the most importantwe provide additional context derived from other sources (e.g., IEEE, UL, CPUC). 


\subsection{Involvement in Ongoing, Multi-party Engagement}

Some utilities described their approach to implementing advanced inverters as system-wide, and another described a "hot spot" approach that targets substations where the functional benefits would be greatest. All participants expressed a need to work directly with stakeholdersincluding inverter manufacturers, regulators, standards committees, solar developers, and PV customers - to implement the programs. Utility participants said, for example, that the role of regulatory commissions and standards working groups is to specify the permissible inverter functions that utilities can employ, and that manufacturers are responsible for producing equipment that complies with the standards and with utility specifications. Participants also emphasized the importance of clearly communicating with the solar industry and end users to ensure compliance with changes to interconnection rules allowing for advanced inverter functionality. Additionally, because the market for advanced inverters is relatively new, one participant expected consolidation in the inverter sector as companies are acquired, merge, or fold; this could jeopardize long-term consumer needs for warranty claims, spare parts, and monitoring services.

\subsection{Inability of Standards to Keep Pace with Technological Advances}

Utilities interviewed were anticipating the final versions of codes and standards that currently are being revised. Utility expectations for advanced inverter functionality differ, and multiple participants stated that no advanced inverter is available as "off-the-shelf" technology. Rather, utilities must partner with inverter manufacturers to define advanced inverter function set points for each utility's unique specifications. Participants expressed the hope that the updated standards will produce common functional solutions for the broader market.

Interconnecting DER to the grid requires compliance with a number of standards governing safety, reliability, and electrical performance. Three main standards have a direct impact on the ability of utilities and solar companies to deploy and operate advanced inverters in the United States: the National Electrical Code (NEC), Underwriters Laboratories (UL) 1741, and IEEE 1547 (see Appendix D for more detail on these standards). The NEC addresses the safe installation of electrical wiring and equipment. The UL 1741 standard is an equipment safety standard that is used to certify that a specific piece of equipment as safe for a given use. By contrast, IEEE 1547 is an interconnection standard that regulates how an inverter may impact electrical conditions at the point of common coupling (PCC) when interconnected to an electrical system. Because the existing versions of UL 1741 and IEEE 1547 (IEEE 1547-2003) were written prior to the development of advanced inverters, those devices cannot be certified as safe, nor can they perform their advanced functions when interconnected to the grid. ${ }^{1}$

Currently, UL 1741 and IEEE 1547-2003 are being revised to accommodate the expanded functionality of advanced inverters. The recent IEEE 1547a-2014 standard was a first step in this

\footnotetext{
${ }^{1}$ In 2014, an amendment to IEEE 1547-2003, titled IEEE 1547a-2014, removed the prohibition on distributed generation actively regulating voltage at the PCC and allowed grid operators to coordinate active voltage control with DER operators, if desired. Additionally, IEEE 1547a-2014 extends the default clearing times for distributed resources during voltage or frequency anomalies, and allows grid and DER operators to specify even more lenient ride-through settings collaboratively. This amendment is designed to increase the contribution of distributed generation to overall grid reliability.
} 
process, as it establishes expanded ride-through settings and permits active voltage control at the PCC if coordinated between DER owners and grid operators. However, other advanced inverter capabilities still cannot be UL certified for many U.S. uses until the changes to both standards are finalized — which is delaying advanced inverter deployment. This delay is driven in part by widespread U.S. adoption of the two standards; of the 44 states that have mandatory, statewide interconnection standards, Texas is the only one that does not explicitly refer to either UL 1741 or IEEE 1547. Even in states without statewide interconnection standards, many utilities have incorporated both the UL and IEEE standards into their own interconnection procedures to ensure safety and reliability. Figure 2 illustrates how other key regulations for distributed generation rely on these two standards, and how these dependencies have impacted deployment of advanced inverters. The following subsections discuss the status of the revision processes for these critical standards.

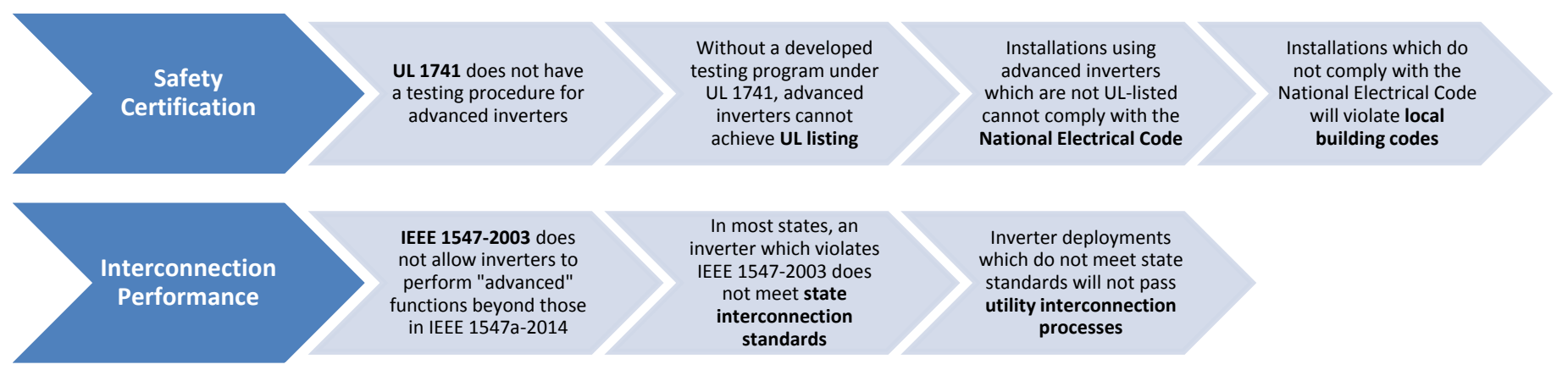

Figure 2. How regulations for distributed generation depend on IEEE 1547 and UL 1741.

\subsubsection{California Rule 21 and the Smart Inverter Working Group}

Much of the impetus for the ongoing revisions to UL1741 and IEEE 1547 has come from California, which boasts the largest U.S. DGPV market. In January 2013, regulators at the CPUC and California Energy Commission (CEC) jointly convened the Smart Inverter Working Group (SIWG). This diverse group — which includes utilities, solar installers, equipment manufacturers, and other stakeholderswas tasked with recommending modifications to California's Rule 21, the tariff under which the state's major investor-owned utilities are required to interconnect generation facilities to the distribution system.

Neither UL nor IEEE had initiated revisions to enable advanced inverter functionality, and by 2013 the CPUC, CEC, and SIWG were prepared to develop their own standards (if

Identifying Locational Benefits of Advanced Inverters
through Distribution Resource Planning-In addition
to the SIWG's effort to revise Rule 21, California is
also addressing advanced inverter use through CA AB
327 , under which each of the three investor-owned
utilities are required to produce distribution resource
plans (DRPs). These DRPs will define locational
benefits of-and identify optimal locations for-DER
systems. Later in the DRP process, utilities include the
use of advanced inverter functions (e.g., volt-VAR
control) to ensure safe and reliable distribution
operations. Although efforts to incorporate advanced
inverters into broader distribution management and
planning are in their infancy, there is long-term
potential for these assets to play a crucial role.


necessary) to allow the use of advanced inverters. California's urgency to update the standards was driven by its rapidly proliferating DGPV market and the associated grid-integration challenges that must be addressed to ensure reliability, as was demonstrated in high-penetration regions such as Hawaii and Germany. Further, it was becoming clear that standards originally designed to maintain grid reliability actually might threaten it. The requirement for DERs to trip offline during voltage or frequency anomalies, for example, has changed quickly from a necessary precaution to a serious hazard to overall system stability, as evidenced by system events in Germany and Italy.

To enable advanced inverters to perform beneficial grid functions rapidly, the SIWG proposed a three-phase process.

- Phase 1 would identify seven high-value functions that advanced inverters could perform autonomously based on static set-points or predefined operational curves. These were seen as "the biggest bang for the buck," increasing overall system stability without the need for expensive communications infrastructure.

- Phase 2 would develop communications standards for the interactions between utilities, DER aggregators, and individual DER facilities. This step required a technology-neutral approach that would also facilitate the deployment and engagement of non-photovoltaic DERs such as storage, demand response, smart home systems, and electric vehicles.

- Phase 3 would identify additional advanced functions - beyond the seven identified in Phase 1 -which also might be required of interconnected facilities through Rule 21. These additional functions could be either autonomous or require communications infrastructure as outlined in the Phase 2 standards.

On December 18, 2014, the CPUC approved the Phase 1 recommendations of the SIWG to require the seven additional autonomous functions under Rule 21. The three main California investor-owned utilities were given 30 days to modify and resubmit their Rule 21 tariffs to reflect these changes. Under the CPUC's ruling, the effective date of these changes was set as the later of either December 31, 2015, or 12 months after UL 1741 is updated to accommodate SIWG's Phase 1 recommendations. Additionally, the most recent draft of SIWG Phase 2 recommendations on communications standards was issued on February 28, 2015, but it has not yet been taken up by the CPUC. Phase 3 discussions of additional advanced functions to be added under Rule 21 are still ongoing as of September 2015.

\subsubsection{UL 1741 SA}

Underwriters Laboratories currently is creating a supplement to its 1741 standard, UL 1741 SA, titled "Supplement for Grid Support Utility Interactive Inverters." The supplement encompasses advanced inverter functionalities required in California as a result of the Smart Inverter Working Group. This expansion will require the development of new test plans and acceptable behavior for devices when they are performing advanced functions. Prior to public release, a preliminary review and comment period for the standard must be completed; the standard then must be passed by the Standards Technical Panel. Underwriters Laboratories expects the UL 1741 SA supplement encompassing enhanced functionality to be published in fall of 2015; it had not yet been released as of September 2015. 
The publication of the expanded UL 1741, however, will not immediately permit the installation of advanced inverters. Rather, manufacturers must certify their equipment under the updated standard by completing UL's testing process. For a device that already has been certified under the existing UL 1741 and simply has received software updates to enable advanced functions, expanded certification could be obtained in as little as one to two months. Inverters requiring substantial hardware changes or those featuring entirely new designs to offer advanced functionality, however, could take as long as four months to certify.

As noted, the final ruling on the SIWG's Phase 1 recommendations to the CPUC makes an explicit linkage between the publication of UL 1741 SA standard and the effective date of the Rule 21 updates. This could trigger a rush among manufacturers to certify their equipment ahead of the one-year deadline rather than risk being shut out of the large California market.

Underwriters Laboratories has noted the possibility of an increase in applications for certification following the release of the new standard, and it believes it is well positioned to meet the certification needs of manufacturers in advance of the one-year Rule 21 deadline.

\subsubsection{IEEE 1547 Full Revision}

The IEEE 1547 Full Revision process establishes a framework under which inverters are permitted to perform various advanced functions. The standard strictly governs the behavior of devices - not limited to inverters - at the PCC. The revision was spurred in part by the SIWG's recommended Rule 21 updates. In the past, Rule 21 relied on IEEE 1547 to specify acceptable DER behavior at the PCC, but some of the approved Phase 1 functions go beyond those permitted in previous revisions of IEEE 1547.

The ongoing revision is intended to be comprehensive, with all clauses subject to review. It is focused on enabling greater penetration of DERs including DGPV equipped with advanced inverters. Under a high-penetration scenario in which DERs comprise an ever-larger share of energy supplied to the grid, the required behaviors of those resources also must change, shifting from a "do no harm" role to one of active grid support. For example, frequency and voltage ridethrough specifications in the updated IEEE 1547 might define larger regions under which devices must remain connected, in contrast to the must-trip zones under the existing IEEE 15472003 and 1547a-2014. Discussions during the revision process have included voltage regulation and power factor controls - two key advanced inverter capabilities that could increase the ability of specific feeders to host more DERs. Balloting for the full IEEE 1547 revision has been forecast for fall 2016 (Sun 2015).

\subsection{Need for New Communications Infrastructure and Protocols}

All interview participants repeatedly highlighted the need for communications infrastructure and protocols to make inverters an integrated grid asset that is interoperable with other infrastructure. This includes the ability of grid operators to work with devices from various manufacturers as well as existing distribution equipment, metering and billing systems, and other utility systems. Participants described the integration of advanced inverters with distribution management systems and DER management systems as long-term goals, but they cautioned that these changes would require significantly more work before becoming operational.

Utilities also described a tradeoff among communications-infrastructure options: more bandwidth enables greater real-time functionality and control but at a greater implementation 
cost. To put this infrastructure into service, communications standards must be implemented to ensure compatibility with existing communications networks and other DER needs. Some utility participants described plans to install more robust communications capabilities on inverters in specific areas and to rely on autonomous functions or more limited bandwidth in others. Advanced inverters could autonomously provide some enhanced functionality based on static set-points, which can be defined at installation and then can later be adjusted by inverter technicians. These autonomous functions do not require communications connectivity or operator dispatch. Other functions require more frequent (approaching real-time) communications to realize their full benefit. In our interviews, several utilities described the significant challenges inherent in establishing the communications infrastructure to interact with advanced inverters. Nevertheless, these same utilities unanimously asserted that the effort and cost of this infrastructure would be worth the incremental benefit provided by communicationsreliant functions.

The SIWG update of California's Rule 21 indicates the significant complexity involved in developing standards for advanced inverter communications infrastructure. The SIWG deliberately avoided all discussion of communications and communications-dependent functions in Phase 1, instead focusing on a small set of high-value functions that could be performed autonomously. Discussions of communications-system design and standards were entirely deferred to Phase 2, from which the SIWG delivered its recommendations to the CPUC in February 2015. Participants waited until Phase 3, which began in early 2015, to begin discussing advanced functions that rely on communications for successful operation. This process bypassed the technical complexity and consensus-building challenges of Phase 2 and Phase 3 to achieve the benefits of Phase 1 functions as quickly as possible.

The following subsections discuss the relationship between advanced inverter functionality and communications, as well as the elements of a communications infrastructure.

\subsubsection{Relationship Between Advanced Functionality and Communications}

The Phase 3 work of the SIWG highlights the robust capabilities of communications-enabled advanced inverters. Table 2 (below) highlights which inverter functions generally are considered autonomous and which require some level of communications connectivity. Autonomous functions that generally rely on static parameters also can benefit from adding a communications system that enables easier and more frequent adjustment of those parameters. 
Table 2. Autonomous Versus Non-Autonomous Inverter Functions

\begin{tabular}{|c|c|c|c|c|}
\hline \multicolumn{2}{|c|}{ Description } & \multirow{2}{*}{$\frac{\text { Functions }}{\text { Low- / High-voltage ride-through }}$} & \multicolumn{2}{|c|}{$\begin{array}{l}\text { Associated } \\
\text { Proceedings and } \\
\text { Standards }\end{array}$} \\
\hline \multirow[t]{11}{*}{ Autonomous } & \multirow{6}{*}{$\begin{array}{l}\text { - No } \\
\text { communications } \\
\text { architecture } \\
\text { needed } \\
\text { - Behavior } \\
\text { controlled by } \\
\text { inverter operating } \\
\text { parameters } \\
\text { - Parameters } \\
\text { defined at system } \\
\text { commissioning or } \\
\text { later }\end{array}$} & & \multirow{7}{*}{$\begin{array}{l}\text { SIWG } \\
\text { Phase } 1\end{array}$} & \multirow{11}{*}{$\begin{array}{c}\text { IEEE } \\
1547 a- \\
2014\end{array}$} \\
\hline & & Low- / High-frequency ride-through & & \\
\hline & & $\begin{array}{l}\text { Volt-var control } \\
\text { (via dynamic reactive power injection) }\end{array}$ & & \\
\hline & & Anti-islanding & & \\
\hline & & $\begin{array}{l}\text { Ramp-rate controls } \\
\text { (for default/emergency conditions) }\end{array}$ & & \\
\hline & & $\begin{array}{l}\text { Provide reactive power } \\
\text { (via fixed power factor) }\end{array}$ & & \\
\hline & \multirow{5}{*}{$\begin{array}{l}\text { - Parameters can } \\
\text { be adjusted, } \\
\text { behavior activated } \\
\text { or deactivated at } \\
\text { later date via } \\
\text { remote or on-site } \\
\text { changes }\end{array}$} & Reconnect via "soft-start" & & \\
\hline & & Frequency-watt & \multirow{4}{*}{$\begin{array}{l}\text { SIWG } \\
\text { Phase } 3\end{array}$} & \\
\hline & & Voltage-watt & & \\
\hline & & Dynamic current support & & \\
\hline & & Smooth frequency deviations & & \\
\hline \multirow[t]{8}{*}{$\begin{array}{l}\text { Non- } \\
\text { Autonomous }\end{array}$} & \multirow{8}{*}{$\begin{array}{l}\text { - Communications } \\
\text { and control } \\
\text { infrastructure } \\
\text { required } \\
\text { - Direct control of } \\
\text { inverter behavior } \\
\text { - Control from } \\
\text { remote operator } \\
\text { commands or } \\
\text { feedback, based } \\
\text { on conditions at } \\
\text { point of common } \\
\text { coupling }\end{array}$} & $\begin{array}{l}\text { Command DER to } \\
\text { connect/disconnect }\end{array}$ & \multirow[t]{8}{*}{$\begin{array}{l}\text { SIWG } \\
\text { Phase } 3\end{array}$} & \\
\hline & & Limit real power & & \\
\hline & & Set real power & & \\
\hline & & Provide black-start capability & & \\
\hline & & Respond to real power pricing signals & & \\
\hline & & $\begin{array}{l}\text { Participate in automatic generator } \\
\text { control (AGC) }\end{array}$ & & \\
\hline & & $\begin{array}{l}\text { Provide spinning reserves or bid into } \\
\text { market }\end{array}$ & & \\
\hline & & $\begin{array}{l}\text { Update static set points for } \\
\text { autonomous functions } \\
\text { (fixed power factor, volt-var curves, } \\
\text { voltage ride-through, frequency ride- } \\
\text { through) }\end{array}$ & & \\
\hline
\end{tabular}

\subsubsection{Elements of a Communications Infrastructure}

To link with advanced inverters in the field, utilities must design a communications infrastructure by choosing from among multiple options at each link in the communications chain. Many protocols and transfer media exist, each offering different benefits and drawbacks in terms of cost, security, interoperability with existing systems, and flexibility for incorporating future applications. An exhaustive comparison of these alternatives is beyond the scope of this 
report, but Table 3 shows some of the options utilities have for each element of their communications infrastructure; SIWG-recommended elements are highlighted in bold. Brief descriptions of each layer and the listed examples are provided in Appendix E.

Table 3. Utility Options for Communications Infrastructure

\begin{tabular}{lll}
\hline Communications Layer & Layer Function & Examples of Layer \\
\hline Data/information model & $\begin{array}{l}\text { Provide data frameworks to } \\
\text { describe electronic equipment } \\
\text { states and functions }\end{array}$ & $\begin{array}{l}\text { IEC } 61850 \\
\text { OpenADR } \\
\text { Common Information Model }\end{array}$ \\
Utility/“application" protocol & $\begin{array}{l}\text { Standardize data exchange } \\
\text { between utility assets and DERs }\end{array}$ & SEP 2.0 (IEEE 2030.5) \\
\hline Communications/"transport" protocol & $\begin{array}{l}\text { Enable data transfer over physical } \\
\text { media }\end{array}$ & Internet Protocol: TCP/IP \\
\hline Communications method/media & $\begin{array}{l}\text { Provide the infrastructure for data } \\
\text { transfer between field assets and } \\
\text { control centers }\end{array}$ & $\begin{array}{l}\text { Cellular GPRS } \\
\text { Public Internet }\end{array}$ \\
\hline Facility/DER/“application" protocol & $\begin{array}{l}\text { Provide means of controlling one or } \\
\text { more DERs at a single premises }\end{array}$ & AMI Network \\
\hline & SEP 2.0 (IEEE 2030.5) & ModBus
\end{tabular}

\subsection{Lack of Compensation Mechanisms for Ancillary Services}

Utility participants described numerous functional benefits from advanced inverters, such as power-quality enhancements and curtailment - known collectively as ancillary services. Today, however, inverters almost always belong to PV customers and PV developers. Interview participants acknowledged that another challenge to realizing the benefits of advanced inverters is the lack of widely used mechanisms to compensate PV owners for ancillary services.

Several utilities are launching pilot projects to determine the technical capabilities of advanced inverters and the monetary value they could provide. Overall, participants expressed that the monetary value of advanced inverter functionality is currently realized much more easily if the utility owns the PV array, inverter, and all associated equipment. Without a compensation framework to transfer financial benefits between equipment owners, the greatest savings are achieved by letting all benefits accrue to the utility. Utility-owned DGPV—such as that approved for deployment in Tucson Electric Power Company (TEP) and Arizona Public Service (APS) territories (see Section 5) - bypasses the compensation and rate-making challenges inherent to controlling third-party-owned systems, and enables quicker experimentation and results. 
Non-utility-owned PV presently dominates the DER market, and seems poised to do so in the foreseeable future. Therefore, enabling utilities to access the benefits of advanced functionality and compensating system owners appropriately will become an increasingly pressing issue. New York's K-Solar program exemplifies what happens today with the lack of a consistent compensation framework. During our interview with the PV owner, New York Power Authority, staff stated that they had been willing to work with local utilities to enable advanced inverter functionality for their school-based solar systems, but that this plan was ultimately abandoned because of the lack of a standard compensation scheme.

At the transmission level, compensation mechanisms exist for ancillary services provided by advanced inverters. PJM, for example, provides for a "capability payment" under the tariff Schedule 2 for reactive power and voltage control. It is provided as a base cost of service, but PJM also pays reactive services providers the difference between the locational marginal price and the seller's offer price for energy, depending on whether the real power out of the provider's resource is reduced or increased (PJM Tariff).

Compensation mechanisms for ancillary services are especially important when a generating asset must forego some real power output - and associated revenue - to supply reactive power instead. Although it is possible for an inverter to supply VARs in addition to maximum real power output, an oversized inverter is required. The larger inverter costs more to install, and if the owner is not compensated for the additional ancillary services, then the more costly investment cannot be justified.

In contrast, as part of the interconnection agreement for distribution-level commercial PV, utilities commonly stipulate that the PV asset must operate off unity power factor as a condition for interconnection approval. For projects installed at the end of a distribution feeder (as at many industrial parks), for example, the PV owner often is asked to operate at 0.95 leading power factor and to inject VARs back to the distribution system to compensate for inductive loads. Although using inverter settings this way can avoid costly infrastructure upgrades for the utility, the PV owner is not compensated for the loss of real power production or for the grid-support functions provided. Additionally, the utility often reserves the right to mandate a power factor adjustment at any point in the PV system's operational lifetime. Financiers typically accept this stipulation as boilerplate interconnection-agreement language, but it can potentially increase financial risk over the 20- to 25-year life of a PV asset.

\section{Arizona's Deployment Strategies and Solution Pathways}

As part of our interview process, APS and TEP agreed to provide additional information to illustrate their advanced inverter deployment processes. In December 2014, both utilities received approval from the Arizona Corporation Commission to offer rooftop PV installation programs to their customers (AZCC 2014a, AZCC 2014b). In return for financial compensation - a monthly "rooftop lease" payment from APS or a long-term contract for a fixed bill from TEP - the utilities will finance, own, and operate PV systems on residential customer rooftops. Under this arrangement, the systems will interconnect to the distribution system on the utility side of the meter. In their program filings with the Arizona Corporation Commission (AZCC), staff at both utilities cited the opportunity to own and control a distributed fleet of 
advanced inverters as one of the key benefits of their respective programs (APS 2014, AZCC 2014c).

A primary program objective for both utilities is to verify the capabilities and potential benefits of advanced inverters. One of the purported benefits of advanced inverters coupled with DGPV systems is the ability to defer otherwise-necessary system upgrades or maintenance by reducing net loads or stabilizing voltage. Both utilities believe that their programs will provide sufficient data for assessing whether advanced inverters actually provide such a benefit. Furthermore, both say that this data collection and performance verification will be much easier when all physical assets in the operational chain are utility owned. Specifically, they think that the logistics of communications infrastructure and issues of operational access and adjustments will be streamlined, and that examining the complex issues of compensating customer- or third-partyowned systems for advanced capabilities can be deferred until the value of these capabilities is better understood.

Both APS and TEP expressed interest in the ability of advanced inverters to mitigate local stability issues and support wider-scale system reliability via expanded voltage and frequency ride-through settings. Arizona Public Service highlighted two specific use cases for advanced inverters in its rooftop PV program. The first is deploying utility DGPV on load-stressed feeders, where peak loads approach the maximum conductor capacity. In this case, APS will study whether introducing utility-owned DGPV could reliably deliver peak-load reductions while reducing the cycling of tap-changing transformers serving those segments. The second use case, somewhat counterintuitively, involves feeders already experiencing high penetration of customer- or third-party-owned PV. In these situations, adding utility-owned PV with advanced inverters might help mitigate voltage fluctuations along the feeder caused by existing DGPV, thus improving power quality, reducing the risk of voltage violations, and reducing cycling of distribution equipment.

Each utility described challenges related to the lack of market readiness of advanced inverter technologies. Because of the current unavailability of UL certification for advanced inverter functionality, one APS engineer remarked that he "might not even be able to stick [an advanced inverter] on a house." The TEP noted similar challenges and also that it has been forced to work hand-in-hand with manufacturers to enable the "latent" advanced capabilities of the inverters, because these functions are not available "off the shelf." This collaboration will benefit both parties in the long run, as TEP plans to provide real-world operational data to its partner manufacturers to improve their product offerings.

Another major challenge to deploying utility-controlled advanced inverters is establishing realworld, real-time communications infrastructure. As Marc Romito of APS noted, "real-time" in this scenario could describe a response time of anywhere from two seconds to five minutes. The path each utility chooses for communications will be influenced by its existing information technology assets in the field. APS developed an advanced metering infrastructure (AMI) network, and TEP implemented an automatic meter reading (AMR) system which allows the remote collection of customer energy use data but has fewer data-collection and transfer capabilities than the APS system. APS suggested that it might leverage its existing AMI system for communications to and from the advanced inverters it controls. TEP is piloting a new cellular-based control scheme across a dozen locations, though it plans to eventually transition to 
a proprietary wireless network for its full program deployment. Both utilities described real-time inverter communications as a difficult but worthwhile logistical effort, because it will unlock high-value advanced capabilities such as volt-VAR control and real-power curtailment. Both also noted that - because of the strong seasonality of load factors and capacity factors in Arizonacommunications infrastructure should enable the remote adjustment of operating parameters for otherwise-autonomous functions. This capability will reduce operations and maintenance costs by saving labor hours, travel for site visits, and other fieldwork that would otherwise be required for onsite adjustments of these parameters.

Lastly, both utilities indicated that advanced inverters are not a standalone solution to distribution issues but rather an important element of future distribution system management. Integrating the capabilities of advanced inverters will be important for both utilities as new DERs - such as energy storage, electric vehicles, demand-side management programs, and increased rooftop PV deployment — combine to create a more variable and challenging environment for distribution engineers in the future.

\section{Conclusion}

Our research elaborates the perspectives on advanced inverters from seven utilities, a regional transmission operator, an inverter manufacturer, a leading solar developer, and a consortium for grid codes and standards. These participants identified several benefits they expect from advanced inverters as well as several challenges to implementing the technology.

- Benefits

○ Improvement in system reliability and power quality

○ Increase in distribution-network visibility through sensor data

- Potential deferral of utility grid capital investments.

- Challenges

- Involvement in ongoing, multi-party engagement

- Inability of standards to keep pace with technological advances

- Need for new communications infrastructure and protocols

○ Lack of compensation mechanisms for ancillary services.

Our report provides additional context on the latter three challenges, which participants identified as the most important. Following is a brief discussion of these three challenges, along with emerging solutions.

The updating of electric-system standards generally proceeds slowly and deliberately, and the current versions of two particular standards - UL 1741 (addressing equipment safety) and IEEE 1547 (addressing interconnection) — are delaying use of advanced inverters nationwide.

California's urgent need to accelerate advanced inverter deployment, however, is helping to stimulate sweeping revisions of the standards. We anticipate that these pending updates not only will ensure the safe incorporation of new functions of advanced inverters into individual systems and the grid, but also will enable the inverters to provide active grid support. Additionally, the updates will likely promote progress toward mass-produced advanced inverters with common 
functionality, satisfying the desire we heard from interview participants for "off-the-shelf" products. In any case, the updates should remove the standards-related barriers to advanced inverter deployment.

Another critical challenge is establishing the communications capabilities needed to realize the grid-support potential of advanced inverters. Many communications options are available, and as the capabilities of the options increase so does their cost. To balance the cost-benefit tradeoff, some of the utilities we interviewed are planning hybrid approaches that relegate advanced inverters in certain areas to autonomous or low-bandwidth operation, and enable robust connectivity on inverters in other areas. Overall, our utility participants agreed that the benefits of establishing communications infrastructure for advanced inverters outweigh the associated complexity and costs.

Lastly, the lack of mechanisms to compensate non-utility PV owners for providing ancillary services presents a challenge to realizing the full potential of advanced inverters. Some utilities, including APS and TEP, are experimenting with utility ownership and control of PV systems mounted on customers' rooftops. Under this framework, utilities can streamline operational logistics and avoid complex financial compensation issues, and can assess the value of the services they receive from the advanced inverter-enabled systems. Results from such projects then can inform the development of future mechanisms for compensating non-utility PV owners. This is important because non-utility ownership seems likely to remain the dominant form of distributed PV deployment in the foreseeable future.

The amount of experience and data from advanced inverter use will increase dramatically over the next several years as the new electric-system standards come into effect, pilot-program results become available, and many more advanced inverters are deployed. Will the anticipated benefits materialize? How much will they be worth? How will the value be distributed among multiple stakeholders? What role will advanced inverters play in an electric system that features increasing amounts of DERs, including energy storage, electric vehicles, demand-side management, and rooftop PV? Such questions, along with the emerging data, will present many avenues for additional research aimed at quantifying the benefits and challenges associated with advanced inverters. 


\section{References}

APS (Arizona Public Service). 2014. Letter to Arizona Corporation Commission Re: Clarification of Need for A2 Sun DG, 2014 RES Implementation Plan E-01345A-13-0140 and 2015 RES Implementation Plan E-01 345A-14-0250. December 3, 2014. Arizona Corporation Commission. http://images.edocket.azcc.gov/docketpdf/0000158438.pdf

AZCC (Arizona Corporation Commission). 2014a. In the Matter of Arizona Public Service Company for Approval of Its 2014/2015 Renewable Energy Standard Implementation Plan for Reset of Renewable Energy Adjustor. December 23, 2014. Docket No. E-01345A-13-0140. http://images.edocket.azcc.gov/docketpdf/0000159388.pdf

AZCC (Arizona Corporation Commission). 2014b. In the Matter of the Application of Tucson Electric Power Company for Approval of Its 2015 Renewable Energy Standard Implementation Plan. December 31, 2014. Docket No. E-01933A-14-0248. http://images.edocket.azcc.gov/docketpdf/0000159167.pdf

AZCC (Arizona Corporation Commission). 2014c. In the Matter of the Application of Tucson Electric Power Company for Approval of Its 2015 Renewable Energy Standard Implementation Plan. July 1, 2014. Docket No. E-01933A-14-0248. http://images.edocket.azcc.gov/docketpdf/0000154472.pdf

Bird, L., J. McLaren, J. Heeter, C. Linvill, J. Shenot, R. Sedano, and J. Migden-Ostrander. 2013. Regulatory Considerations Associated with the Expanded Adoption of Distributed Solar. NREL/TP-6A20-60613. Golden, CO: National Renewable Energy Laboratory. http://www.nrel.gov/docs/fy14osti/60613.pdf

BNEF (Bloomberg New Energy Finance). 2014. H1 2014 US PV Market Outlook: Nickel-a-Pop PPAs. New York: Bloomberg New Energy Finance.

Coddington, M., B. Mather, B. Kroposki, K. Lynn, A. Razon, A. Ellis, R. Hill, T. Key, K. Nicole, and J. Smith. 2012. Updating Interconnection Screens for PV System Integration. NREL/TP-5500-54063. Golden CO: National Renewable Energy Laboratory. http://www.nrel.gov/docs/fy12osti/54063.pdf

Davidovich, Ted, and John Sterling. 2014. Unlocking Advanced Inverter Functionality: Roadmap to a Future of Utility Engagement and Ownership. Washington, DC: Solar Electric Power Association.

Denholm, P., R. Margolis, B. Palmintier, C. Barrows, E. Ibanez, L. Bird, and J. Zuboy. 2014. Methods for Analyzing the Benefits and Costs of Distributed Photovoltaic Generation to the U.S. Electric Utility System. NREL/TP-6A20-62447. Golden CO: National Renewable Energy Laboratory. http://www.nrel.gov/docs/fy14osti/62447.pdf

Deutsche Bank Markets Research. 2015. Crossing the Chasm. Frankfurt: Deutsche Bank.

DNP Users Group. 2005. A DNP3 Protocol Primer. Accessed August 24, 2015. http://www.dnp.org/AboutUs/DNP3\%20Primer\%20Rev\%20A.pdf 
EPRI (Electric Power Research Institute). 2014. The Integrated Grid: Realizing the Full Value of Central and Distributed Energy Resources. Palo Alto, CA: Electric Power Research Institute. http://www.epri.com/abstracts/Pages/ProductAbstract.aspx?ProductId=000000003002002733\& Mode= download

GTM Research and SEIA (Solar Energy Industries Association). 2015. U.S. Solar Market Insight Report, Q2 2015. Washington, DC: Solar Energy Industries Association.

IEEE. Adoption of Smart Energy Profile 2.0 Application Protocol Standard. IEEE Std 2030.52013. pp.1,348. November 11, 2013.

http://ieeexplore.ieee.org/stamp/stamp.jsp?tp=\&arnumber=6662361\&isnumber=6662360.

Modbus. "Modbus FAQ." 2015. Accessed August 24, 2015. http://www.modbus.org/faq.php.

National Institute of Standards and Technology. Summary of Use, Application, Cybersecurity, and Functionality of Smart Grid Interoperability Standards Identified by NIST. 2010. Accessed August 24, 2015. http://collaborate.nist.gov/twikisggrid/pub/SmartGrid/NISTStandardsSummaries/IEC 61850 Narrative 10-6-2010.doc

NEMA (National Electrical Manufacturers Association). 2015. "Adoption of the National Electrical Code." Accessed July 2015. http://www.nema.org/Technical/FieldReps/Pages/National-Electrical-Code.aspx

PJM Tariff. “Attachment O Form of Interconnection Service Agreement.” Appendix 2 § 4.7.4.

PJM Tariff. "Schedule 2-Reactive Supply and Voltage Control from Generation or Other Sources Service." Section 3.2.3B of Appendix to Attachment K.

Seal, B. 2014. Common Functions for Smart Inverters, Version 3. Palo Alto, CA: Electric Power Research Institute.

Simmins, J. J. "The impact of PAP 8 on the Common Information Model (CIM)." Power Systems Conference and Exposition (PSCE), 2011 IEEE/PES, pp.1, 2, 20-23. March 2011. Accessed July 2015.

http://ieeexplore.iee.. rg/stamp/stamp.jsp?tp=\&arnumber $=5772503 \&$ isnumber $=5772439$

Sun, C. "DG Standards Updates." March 27, 2015. Accessed August 24, 2015. https://www.cavs.msstate.edu/iPCGRID_Registration/presentations/2015/Sun _ iPCGRID_2015 DG_Interconnection_Standard_Update.pdf

Underwriters Laboratories. 2010. UL Standard for Inverters, Converters, Controllers and Interconnection System Equipment for Use with Distributed Energy Resources. UL Standard 1741 .

UL (Underwriters Laboratories). 2012. "Inverters in Photovoltaic Systems." Electrical Connections (January). Accessed July 2015. http://www.ul.com/global/documents/corporate/aboutul/publications/newsletters/ electricalconnections/January $12 \% 20 . p d f$ 
Varma, R. K., B. Das, I. Axente, and T. Vanderheide. 2011. "Optimal 24-Hr Utilization of a PV Solar System as STATCOM (PV-STATCOM) in a Distribution Network." Proceedings of the 2011 IEEE Power and Energy Society General Meeting: 1-8.

WEIL (Western Electric Industry Leaders) Group. 2013. "Letter to Governors, Commissioners, and Legislators." August 7, 2013. WEIL Group.

http://weilgroup.org/WEIL_Smart_Inverters_Letter_Aug-7-2013.pdf

Wirth, Harry. 2015. Recent Facts About Photovoltaics in Germany. Freiburg: Fraunhofer Institute for Solar Energy Systems ISE. Accessed July 2015.

http://www.ise.fraunhofer.de/en/publications/veroeffentlichungen-pdf-dateien-en/studien-undkonzeptpapiere/recent-facts-about-photovoltaics-in-germany.pdf 


\title{
Appendix A. SEPA's Annual Solar Market Survey Instrument 2015
}

\begin{abstract}
7.) What solar activities do you expect your utility to continue or implement in 2015 ? (Check all that apply)
\end{abstract}

\begin{tabular}{|c|c|c|c|}
\hline Activities & $\begin{array}{l}\text { Currently offerl } \\
\text { Implementing }\end{array}$ & $\begin{array}{l}\text { Planning/ } \\
\text { Considering/ } \\
\text { Researching }\end{array}$ & $\begin{array}{l}\text { Not } \\
\text { Planning/ } \\
\text { No Interest }\end{array}$ \\
\hline \multicolumn{4}{|l|}{$\begin{array}{l}\text { Solar Incentive for Customers (e.g., } \\
\text { rebates, performance) }\end{array}$} \\
\hline \multicolumn{4}{|l|}{$\begin{array}{l}\text { Restructuring of rates or charges to } \\
\text { manage net metering revenue impacts }\end{array}$} \\
\hline \multicolumn{4}{|l|}{ Utility-managed community solar programs } \\
\hline \multicolumn{4}{|l|}{$\begin{array}{l}\text { Third-party managed community solar } \\
\text { programs }\end{array}$} \\
\hline \multicolumn{4}{|l|}{ Value of solar tariff } \\
\hline \multicolumn{4}{|l|}{ Feed-in-tariff } \\
\hline \multicolumn{4}{|l|}{$\begin{array}{l}\text { Renewable/green programs for key } \\
\text { account customers (customers with } \\
\text { highest energy demand [e.g. commercial, } \\
\text { industrial, educational, etc.]) }\end{array}$} \\
\hline \multicolumn{4}{|l|}{$\begin{array}{l}\text { Utility integrated resource plan indicating } \\
\text { solar as a least cost resource }\end{array}$} \\
\hline \multicolumn{4}{|l|}{$\begin{array}{l}\text { Utility-scale solar procurement (ownership } \\
\text { and/or RFPs) }\end{array}$} \\
\hline \multicolumn{4}{|l|}{$\begin{array}{l}\text { Locational deployment (influencing the } \\
\text { location of customer-owned solar energy } \\
\text { facilities) }\end{array}$} \\
\hline \multicolumn{4}{|l|}{ On-bill financing } \\
\hline \multicolumn{4}{|l|}{$\begin{array}{l}\text { Advanced inverter functionality activities } \\
\text { (e.g., customer requirements, R\&D) }\end{array}$} \\
\hline \multicolumn{4}{|l|}{ Energy storage (excluding pumped hydro) } \\
\hline $\begin{array}{l}\text { Solar Energy Production Forecasting } \\
\text { (short-term, operational, employment of } \\
\text { technology and algorithms using weather } \\
\text { data) }\end{array}$ & & & \\
\hline
\end{tabular}




\section{Appendix B. Utilities Implementing or Exploring Advanced Inverters (from SEPA 2015 Survey)}

Utilities that currently are implementing advanced inverter functionality:

- Arizona Public Service (AZ)

- Atlantic City Electric (NJ)

- Avista Utilities (WA)

- Delmarva Power (DE, MD)

- Hawaiian Electric Company, Inc. (HI)

- Kauai Island Utility Cooperative (HI)

- National Grid Massachusetts Electric Co. (MA)

- Niagara Mohawk Power Corp. (NY)

- Pacific Gas \& Electric Company (CA)

- Pepco (Potomac Electric Power) (DC, MD)

- Sacramento Municipal Utility District (CA)

- San Diego Gas \& Electric Company (CA)

- Southern California Edison (CA)

- The Narragansett Electric Co. (RI)

- Tucson Electric Power Company (AZ).

Utilities planning, researching, or considering advanced inverter functionality:

- Anaheim Public Utilities (CA)

- Austin Energy (TX)

- Central Hudson Gas \& Electric Corporation (NY)

- Clark Public Utilities (WA)

- Connecticut Light and Power Company (CT)

- Consolidated Edison Company of New York (NY)

- CoServ Electric (TX)

- CPS Energy (TX)

- Dominion Virginia Power (VA)

- Duke Carolinas (NC, SC)

- Duke Energy Progress (NC, SC)

- Duke Indiana (IN)

- El Paso Electric Co. (NM, TX)

- Georgia Power Company (GA)

- Holy Cross Energy (CO)

- Indianapolis Power \& Light Company (IN)

- Interstate Power and Light Co. (IA)

- Kit Carson Electric Cooperative (NM)

- Long Island Power Authority (NY)

- Los Angeles Department of Water and Power (CA) 
- Minnesota Power (MN)

- Nebraska Public Power District (NE)

- New York Power Authority (NY)

- NV Energy (NV)

- Omaha Public Power District (NE)

- Orange and Rockland (NY)

- Pacific Power (CA, OR, WA)

- Pike County Light \& Power Co. (PA)

- Platte River Power Authority (CO)

- Portland General Electric (OR)

- Public Service Electric \& Gas Company (NJ)

- Public Service of New Hampshire (NH)

- Puget Sound Energy (WA)

- Rockland Electric Company (NJ)

- Rocky Mountain Power (ID, UT, WY)

- Roseville Electric (CA)

- San Miguel Power Association (CO)

- South Carolina Electric \& Gas Co. (SC)

- UNS Electric, Inc. (AZ)

- Vineland Municipal Electric Utility (NJ)

- Westar Energy, Inc. (KS)

- Wisconsin Power and Light Co. (WI)

- Xcel MN—Northern States Power (MN). 


\section{Appendix C. NREL-SEPA Interview Questions Used for Data Collection}

\section{General Utility Information}

Utility and Contact Information

Please answer the following questions about the utility you represent.

Utility Name:

Primary Contact First and Last Name:

Primary Contact Email Address:

Primary Contact Phone:

1) How does your utility perceive smart inverter technology, its applications, challenges and opportunities?

2) What kinds of studies and analysis are being conducted to better understand the technology?

3) Do you require smart inverters for interconnection?

[ ] Yes

[] No

[ ] Details? (write in):

Is your utility considering requiring them?

[] Yes

[ ] No

[ ] Details? (write in): 
4) Is your utility considering/developing protocols (safety, interconnection, deployment strategies) specific to smart inverters?

[ ] Yes

[] No

[ ] Not sure

Please describe the protocols being considered/planned.

5) Is your utility interested in participating in the ancillary markets for frequency and voltage regulation using smart inverters?

[] Yes

[] No

[ ] Details? (write in):

How is your utility planning to participate in the ancillary markets for frequency and voltage regulation using smart inverters?

6) Does your utility see a benefit from third parties using smart inverters? Please describe the pros and cons of third parties using these devices.

7) Who has legal authority for operational setting changes of customer-sited advanced inverters? Who should?

8) Is your utility considering ownership of smart inverters?

( ) Yes

( ) No

( ) Not sure 
What considerations are being given to ownership of advanced inverters?

9) What is the biggest grid integration challenge you would hope to address with advanced inverter functionality?

10) What types of smart inverter applications are being used/considered?

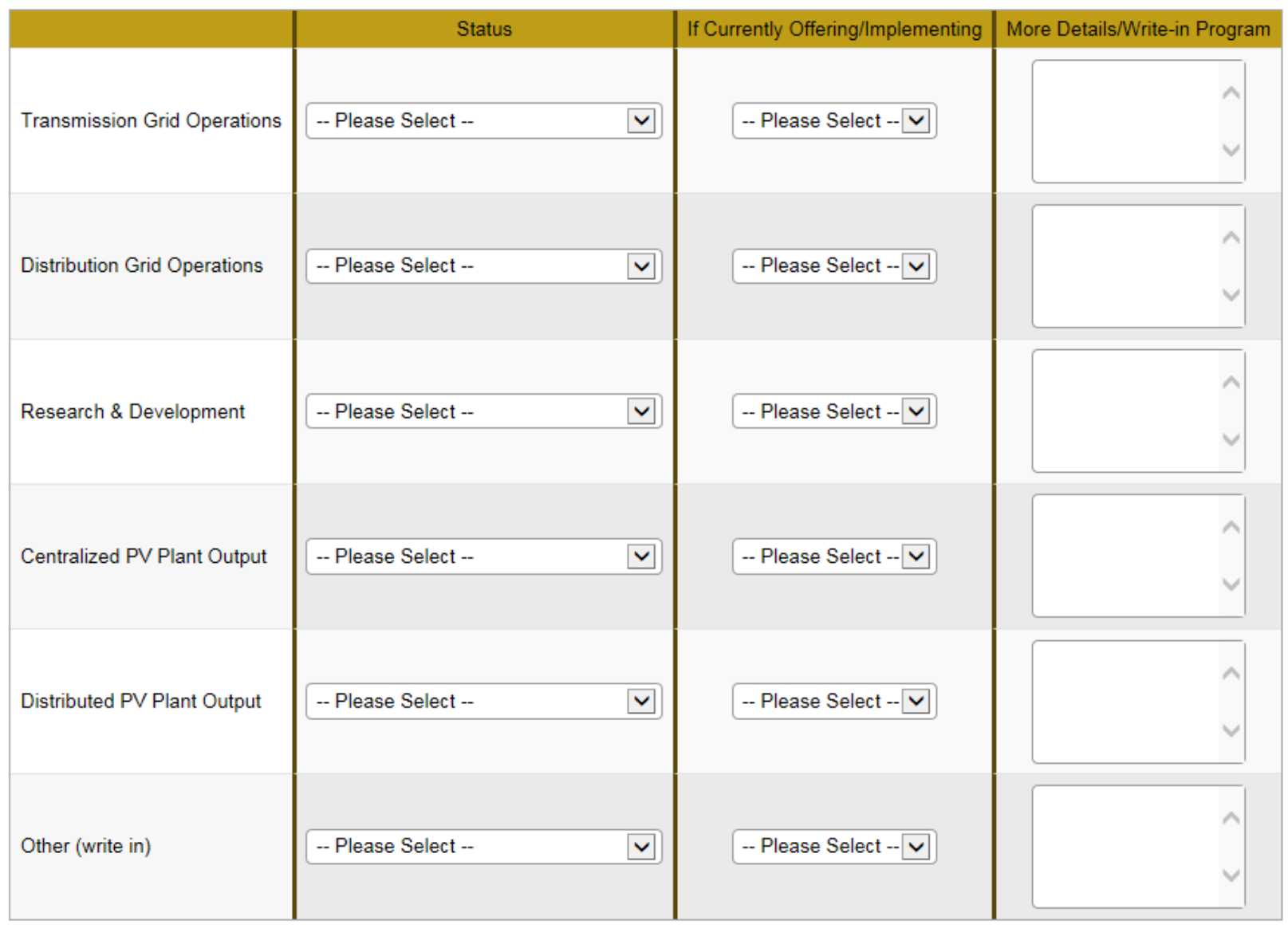




\section{Appendix D. Overview of Advanced Inverter Deployment Standards}

\begin{tabular}{|c|c|}
\hline Standard & Overview \\
\hline NEC & $\begin{array}{l}\text { The NEC is a standards document developed by the National Fire Protection Association that } \\
\text { addresses the safe installation of electrical wiring and equipment. Adoption of the NEC varies } \\
\text { by state, with at least five states implementing each of the 2008, 2011, and } 2014 \text { editions of } \\
\text { the code as of the writing of this report. All } 50 \text { states have adopted the NEC in some form: } \\
\text { most states have adopted the NEC on a statewide basis, though at least } 10 \text { grant some } \\
\text { discretion for adoption to local jurisdictions (NEMA 2015). Three sections of the NEC require } \\
\text { that inverters be UL listed and identified for their intended use (UL 2012): } \\
\text { NEC Section } 690.4 \text { (B)-Solar Photovoltaic (PV) Systems; } \\
\text { NEC Section 690.35(G)-Ungrounded Photovoltaic Power Systems; and } \\
\text { NEC Section 705.4-Interconnected Electric Power Production Sources. }\end{array}$ \\
\hline UL 1741 & $\begin{array}{l}\text { Inverter manufacturers can fulfill the "listing" requirement of the NEC sections above by } \\
\text { certifying their equipment under standards issued by UL, a for-profit standards development, } \\
\text { testing, and certification corporation. The relevant standard for inverters is UL } 1741 \text {, } \\
\text { "Inverters, Converters, Controllers and Interconnection System Equipment for Use with } \\
\text { Distributed Energy Resources." This standard sets all manner of requirements for inverters: } \\
\text { construction specifications for inverter enclosures, external connections, and internal } \\
\text { hardware; protections against injury to persons; external warnings and informational } \\
\text { markings; and electric-output characteristics. In the area of electric performance, UL } 1741 \\
\text { defines testing procedures and acceptable behaviors under a wide range of abnormal } \\
\text { conditions, including short circuits, direct current input miswiring, restricted ventilation, high } \\
\text { temperatures, and voltage spikes. Where the standard discusses the interaction of inverters } \\
\text { with a utility electric system, UL } 1741 \text { explicitly requires conformance with IEEE 1547-2003 } \\
\text { and its companion testing procedure, IEEE } 1547.1 \text { (UL 2010). }\end{array}$ \\
\hline \multirow{7}{*}{$\begin{array}{l}\text { IEEE } \\
1547\end{array}$} & $\begin{array}{l}\text { Approved in } 2003 \text { and reaffirmed in } 2008 \text {, IEEE } 1547-2003 \text { provides technical specifications } \\
\text { governing the interconnection of a DER to the electrical grid. The standard applies to DERs } \\
\text { with an aggregate rating of } 10 \text { megavolt amperes (MVA) or less at the PCC }{ }^{2} \text { and } \\
\text { interconnected at primary or secondary distribution voltages. The specifications of IEEE } \\
1547-2003 \text { define acceptable (or unacceptable) behaviors of the DERs in terms of their effect } \\
\text { on electrical conditions at the PCC. The following provides a partial list of these topics and } \\
\text { the relevant section of the standard. }\end{array}$ \\
\hline & Voltage regulation (4.1.1) \\
\hline & Response to grid faults (4.2.1) \\
\hline & Voltage $(4.2 .3)$ \\
\hline & Frequency (4.2.4) \\
\hline & Unintentional islanding (4.4.1) \\
\hline & $\begin{array}{l}\text { In addition to defining behaviors, IEEE } 1547-2003 \text { outlines a testing and evaluation } \\
\text { procedure to certify that the interconnection of a DER will meet the required conditions } \\
\text { defined above. }\end{array}$ \\
\hline
\end{tabular}

\footnotetext{
${ }^{2}$ The PCC represents the point at which the onsite, local electric power system (local EPS), which may contain one or more distributed resources, connects to the wider grid, or area electric power system (area EPS).
} 


\section{Appendix E. Description of Communication Layer Options}

\begin{tabular}{|c|c|c|c|}
\hline Communications Layer & Purpose & Examples & Description \\
\hline \multirow{3}{*}{$\begin{array}{l}\text { Data/ } \\
\text { information } \\
\text { model }\end{array}$} & \multirow{3}{*}{$\begin{array}{l}\text { Data and information } \\
\text { models provide the } \\
\text { structure for describing } \\
\text { devices, their } \\
\text { functions, and other } \\
\text { operating parameters } \\
\text { of electrical system } \\
\text { operations. }\end{array}$} & IEC 61850 & $\begin{array}{l}\text { IEC } 61850 \text { was } \\
\text { originally designed for } \\
\text { communication } \\
\text { between devices } \\
\text { within a substation, } \\
\text { but has since been } \\
\text { expanded to } \\
\text { distributed energy } \\
\text { resources, hydro } \\
\text { power and wind } \\
\text { power (Summary } \\
2010 \text { ). }\end{array}$ \\
\hline & & OpenADR & $\begin{array}{l}\text { OpenADR provides a } \\
\text { data model strictly } \\
\text { tailored to demand } \\
\text { response devices and } \\
\text { functions. }\end{array}$ \\
\hline & & $\begin{array}{l}\text { Common Information Model } \\
\text { (IEC 61970, IEC 61968) }\end{array}$ & $\begin{array}{l}\text { The Common } \\
\text { Information Model is } \\
\text { a data construct to } \\
\text { describe the physical } \\
\text { infrastructure of the } \\
\text { transmission and } \\
\text { distribution systems } \\
\text { as well as the flow of } \\
\text { power on these } \\
\text { elements (Simmins } \\
\text { 2011). }\end{array}$ \\
\hline \multirow[t]{2}{*}{$\begin{array}{l}\text { Utility/ } \\
\text { "application" } \\
\text { protocol }\end{array}$} & \multirow{2}{*}{$\begin{array}{l}\text { Utility or "application" } \\
\text { protocols allow for } \\
\text { communication } \\
\text { between the local } \\
\text { distribution utility and a } \\
\text { distributed energy } \\
\text { resource (or an } \\
\text { aggregation of them). }\end{array}$} & $\begin{array}{l}\text { SEP } 2.0 \\
\text { (IEEE 2030.5) }\end{array}$ & $\begin{array}{l}\text { SEP 2.0, released in } \\
2013, \text { was explicitly } \\
\text { designed for home } \\
\text { automation and } \\
\text { distributed energy } \\
\text { applications by a } \\
\text { consortium of } \\
\text { communications } \\
\text { technology } \\
\text { organizations (IEEE } \\
\text { Adoption 2013). }\end{array}$ \\
\hline & & $\begin{array}{l}\text { DNP3 } \\
\text { (IEEE 1815) }\end{array}$ & $\begin{array}{l}\text { DNP3 was originally } \\
\text { designed for } \\
\text { communication } \\
\text { between utility master } \\
\text { control stations and } \\
\text { assets in the field in } \\
\text { the early 1990s (DNP } \\
\text { Users Group 2005). }\end{array}$ \\
\hline
\end{tabular}




\begin{tabular}{|c|c|c|c|}
\hline Communications Layer & Purpose & Examples & Description \\
\hline $\begin{array}{l}\text { Communications/ } \\
\text { "transport" protocol }\end{array}$ & $\begin{array}{l}\text { A communications } \\
\text { protocol layer is } \\
\text { necessary to specify } \\
\text { how data should be } \\
\text { packetized, sent, } \\
\text { routed, and received. }\end{array}$ & $\begin{array}{l}\text { TCP/IP } \\
\text { (Internet model) }\end{array}$ & $\begin{array}{l}\text { By far the most widely } \\
\text { used communications } \\
\text { layer is the } \\
\text { combination of } \\
\text { Transmission Control } \\
\text { Protocol (TCP) and } \\
\text { Internet Protocol (IP), } \\
\text { which are most well } \\
\text { known as the basis of } \\
\text { the modern Internet. }\end{array}$ \\
\hline \multirow{5}{*}{$\begin{array}{l}\text { Communications } \\
\text { method/media }\end{array}$} & \multirow{5}{*}{$\begin{array}{l}\text { Communications } \\
\text { methods and media } \\
\text { describe means for } \\
\text { transmitting } \\
\text { communicable data } \\
\text { between devices. } \\
\text { There are many } \\
\text { options for this layer } \\
\text { and the chosen } \\
\text { method will often be } \\
\text { determined by a joint } \\
\text { consideration of cost, } \\
\text { functionality, and } \\
\text { security. }\end{array}$} & Utility Private WAN & $\begin{array}{l}\text { Wide-area networks } \\
\text { (WANs) span a broad } \\
\text { geographic area. } \\
\text { They often use } \\
\text { leased } \\
\text { communication } \\
\text { channels, but utilities } \\
\text { can develop their own } \\
\text { private networks for } \\
\text { greater performance } \\
\text { and security. }\end{array}$ \\
\hline & & Cellular GPRS & $\begin{array}{l}\text { General Packet Radio } \\
\text { Service (GPRS) is a } \\
\text { data service on } 2 G \text { or } \\
3 G \text { mobile networks } \\
\text { which uses the global } \\
\text { system for mobile } \\
\text { communications } \\
\text { (GSM). }\end{array}$ \\
\hline & & Public Internet & $\begin{array}{l}\text { Public Internet } \\
\text { communications use } \\
\text { the same } \\
\text { infrastructure which } \\
\text { provides Internet } \\
\text { service to homes and } \\
\text { businesses. }\end{array}$ \\
\hline & & AMI Network & $\begin{array}{l}\text { AMI networks collect } \\
\text { data from a fleet of } \\
\text { smart meters. }\end{array}$ \\
\hline & & Telecom Provider & $\begin{array}{l}\text { Utilities can partner } \\
\text { with telecom } \\
\text { providers to create } \\
\text { solutions which make } \\
\text { use of wired or } \\
\text { wireless networks. }\end{array}$ \\
\hline
\end{tabular}




\begin{tabular}{|c|c|c|c|}
\hline Communications Layer & Purpose & Examples & Description \\
\hline & \multirow{2}{*}{$\begin{array}{l}\text { Facility-level } \\
\text { communication } \\
\text { protocols enable } \\
\text { communications } \\
\text { between multiple } \\
\text { devices on the same } \\
\text { premises with one } \\
\text { common } \\
\text { communications } \\
\text { connection to the } \\
\text { associated utility } \\
\text { system. }\end{array}$} & $\begin{array}{l}\text { SEP } 2.0 \\
\text { (IEEE 2030.5) }\end{array}$ & $\begin{array}{l}\text { In addition to } \\
\text { communications } \\
\text { between a utility and } \\
\text { a customer, SEP } 2.0 \\
\text { can also facilitate } \\
\text { communications } \\
\text { between devices at } \\
\text { the same location. }\end{array}$ \\
\hline $\begin{array}{l}\text { Facility/DER } \\
\text { "application" protocol }\end{array}$ & & ModBus & $\begin{array}{l}\text { ModBus is a } \\
\text { commonly used } \\
\text { protocol for within- } \\
\text { facility } \\
\text { communications. It } \\
\text { was developed in the } \\
\text { late } 1970 \text { s to enable } \\
\text { communications } \\
\text { between electronic } \\
\text { devices used in } \\
\text { industrial processes } \\
\text { (Modbus 2015). }\end{array}$ \\
\hline
\end{tabular}

